\title{
UMA ABORDAGEM DOS REFLEXOS CONTÁBEIS DECORRENTES DO CANCELAMENTO DAS DESPESAS PÚBLICAS DOS RESTOS A PAGAR DA UNIÃO (1999 - 2003)*
}

\section{A STUDY ON THE ACCOUNTING REFLEXES STEMMING FROM THE ANNULMENT OF GOVERNMENTAL EXPENDITURES FROM THE ACCOUNTS PAYABLE BY THE UNION}

\author{
MAURÍCIO CORRÊA DA SILVA \\ Professor Mestre do Curso de Ciências Contábeis \\ da Faculdade de Ciências Humanas ESUDA - PE \\ E-mail:mauriciocsilva@oi.com.br
}

\section{RESUMO}

Este estudo objetivou analisar e evidenciar os reflexos contábeis decorrentes do cancelamento das despesas públicas dos restos a pagar da União. A identificação, a análise e a discussão foram possíveis a partir da coleta de dados das contas públicas, disponibilizadas pela Secretaria do Tesouro Nacional (STN), no período de 1999 a 2003. Definiuse a hipótese nula de que os reflexos contábeis decorrentes do cancelamento das despesas dos restos a pagar não são significativos em relação às despesas liquidadas. Foram utilizadas as pesquisas exploratórias, bibliográficas, documental, qualitativa e quantitativa. Os resultados revelaram que o cancelamento das despesas públicas dos restos a pagar refletiu contabilmente no valor das despesas que foram consideradas liquidadas e divulgadas pelos poderes e órgãos da União: diminuição das despesas, incorporação de ativos a maior, estorno de exigibilidade, aumento de resultado do sistema financeiro.

Palavras-chave: Contabilidade pública; Despesas liquidadas e despesas reais.

\section{ABSTRACT}

This study intended to analyze and evidence the accounting reflexes due to the cancellation of public expenditures unpaid at the Fiscal yearend of the Union. Related identification, analysis and discussion were based on data of Governmental accounts, made available by the National Treasurey Secretariat (STN), in the period from 1999 to 2003. The basic statistical hypothesis was that the accounting reflexes of such cancellation are not meaningful when compared to the expenditures actually paid. Exploratory, bibliographical, documental, qualitative and quantitative researches were used. The results disclosed that the cancellation of the balance of unpaid Government expenditure influenced, accounting-wise, the amount of paid expenditures as reported by various Governmental levels in relation to -: decrease of reported expenditures, overestimated assets, liability reversal, increase in the results of the Governmental financial system.

Keywords: Public accounting; Liquidated expenditures and actual expenditures. 


\section{INTRODUC̣ÃO}

A contabilidade pública deve evidenciar os fatos ligados à administração orçamentária, financeira, patrimonial e industrial. Deve evidenciar, também, perante a Fazenda Pública, a situação de todos quantos, de qualquer modo, arrecadem receitas ${ }^{1}$, efetuem despesas ${ }^{2}$, administrem ou guardem bens e valores a ela pertencentes ou confiados.

Os serviços de contabilidade deverão ser organizados de forma a permitir o acompanhamento da execução orçamentária e a conhecer a composição patrimonial.

Para Reis (1992), é preciso encontrar um caminho que auxilie a contabilidade a tornar-se um instrumento útil ao gestor $e$ ao contribuinte, pois a este se devem satisfações sobre a utilização dos recursos financeiros.

A contabilidade labora no desafio de estabelecer um mecanismo duradouro de confiança mútua quando produz as demonstrações contábeis necessárias ao processo de comunicação com os usuários externos à entidade (RIBEIRO; RIBEIRO FILHO; FRAGOSO, 2003).

A contabilidade, segundo a abordagem ética, deveria apresentar-se como justa e não enviesada para todos os interessados (IUDíCIBUS, 2004).

\subsection{Caracterização do Problema}

Para Ribeiro Filho (2001), a Lei de Responsabilidade Fiscal (LRF) é mais um esforço na direção da accountability, busca de responsabilidade em duas mãos entre os gestores públicos e os cidadãos/eleitores, pelo desejo de um orçamento, não apenas formalmente equilibrado, mas, fundamentalmente, gerido com eficiência, eficácia e efetividade.

A demonstração utilizada pelo Governo para esclarecer aos cidadãos o montante das despesas, por grupo, discriminando a natureza da despesa, a dotação para o exercício, a despesa liquidada ${ }^{3}$, o saldo da dotação e as receitas (realizadas e as a realizar) é o Balanço Orçamentário.

O detalhamento da execução das despesas por função e das despesas dos restos a pagar por poder ${ }^{4}$ e órgão é evidenciado nas demonstrações pelas quais recebem os mesmos nomes, respectivamente.
As despesas públicas são contabilizadas em três categorias de despesas: realizadas e pagas dentro do exercício financeiro ${ }^{6}$; realizadas e não pagas dentro do exercício financeiro, denominadas de restos a pagar processadas $e$ as despesas não realizadas, mas que foram empenhadas e poderão ser realizadas e pagas no exercício financeiro seguinte, denominadas de restos a pagar não processadas.

Ocorrendo o cancelamento das despesas de restos a pagar (art. 38 da Lei $n^{\circ} .4 .320 / 64^{7}$ ), haverá uma modalidade de receita pitoresca, isto é, uma espécie de receita que não transita pela arrecadação (CRUZ et al., 2001), denominada de "receita figurativa"8 (KOHAMA, 1999).

As despesas de restos a pagar não processadas são consideradas como despesas liquidadas no Balanço Orçamentário (eventos 50.1.468, 54.3.122 e 54.3.009) do ano de inscrição e, caso sejam canceladas no exercício seguinte, terão, como conseqüência, uma compensação de registros contábeis no sistema de resultado (financeiro e patrimonial) para as despesas de materiais e um aumento no sistema de resultado do sistema financeiro para as despesas de serviços (eventos de cancelamento de restos a pagar não processados: 40.1.094 e 40.1.095).

Haverá, igualmente, uma diminuição do valor da despesa que foi considerada liquidada e informada pelos poderes e órgãos no Balanço Orçamentário do ano de inscrição da despesa, em decorrência do cancelamento no ano seguinte.

No caso do cancelamento das despesas dos restos a pagar processados, a baixa da conta contábil de Fornecedores de Exercícios Anteriores ocorrerá com o evento 54.0.379 ${ }^{10}$, como conseqüência, também, no sistema de resultado financeiro (aumento).

Como exemplo de cancelamento de despesas de restos a pagar, observe-se que, em 2002, o Poder Executivo Federal liquidou despesas no montante de 422 bilhões de reais, inscreveu em restos a pagar 24 bilhões e cancelou mais de 6 bilhões de reais ( 5,6 bilhões de restos a pagar não processados e 0,9 bilhões de restos a pagar processados $)^{11}$. $\mathrm{O}$

\footnotetext{
1 Receitas públicas correspondem ao ingresso que, integrando-se ao patrimônio público sem quaisquer reservas, condições ou correspondência no passivo, vem acrescentar seu vulto como elemento novo e positivo. SILVA, Lino Martins da. Contabilidade governamental - um enfoque administrativo. 4. ed. São Paulo: Atlas, 2000.

2 Despesas públicas: conceitualmente, na contabilidade pública, todos os gastos são tratados genericamente como despesa. CRUZ, Flávio da. Auditoria governamental. São Paulo: Atlas, 1997.

3 Despesa liquidada refere-se àquela em que o credor tem o direito adquirido de receber o pagamento, visto que o material foi entregue e/ou o serviço foi prestado, tendo por base os títulos e documentos comprobatórios do respectivo crédito, atestados por quem de direito da administração pública.

4 Poder: uno e indivisível, um atributo do Estado que emana do povo. São poderes da União, independentes e harmônicos entre si, o Legislativo, o Executivo e o Judiciário. LENZA, Pedro. Direito constitucional esquematizado. 7. ed. São Paulo: Método, 2004.

5 Órgão é todo centro de competência, para desempenho de funções, através de um ou de vários agentes, cuja atuação é sempre imputada à pessoa jurídica a que pertence. MEIRELLES, Hely Lopes. Direito administrativo brasileiro. 16. ed. São Paulo: Revista dos Tribunais, 1991.

6 Exercício financeiro - período em que se concretizem a execução orçamentária e a execução financeira. Para informações sobre o exercício financeiro de outros países consultar: GIACOMONI, James. Orçamento público. 12. ed. São Paulo: Atlas, 2003.

7 Art. 38. Reverte à dotação a importância de despesa anulada no exercício; quando a anulação ocorrer após o encerramento deste, considerar-se-á receita do ano em que se efetivar.

8 Receita figurativa: que não se concretiza em entrada de dinheiro e tem contrapartida na "despesa".

9 Evento: código utilizado no Sistema Integrado de Administração Financeira do Governo Federal (SIAFI) para o registro dos atos e fatos administrativos - processamento automático dos restos a pagar não processados.

10 Código de evento utilizado para anulação (baixa) de restos a pagar processados - inscritos em fornecedores do exercício anterior (conta do passivo).

11 Os valores foram extraídos da Demonstração das Despesas da União por Poder e Órgão de 2002 e da Demonstração dos Restos a Pagar por Poder e Órgão de 2002. Disponíveis em: <www.stn.fazenda.gov.br/contabilidade_governamental/gestão_orcamentaria.asp >. Acesso em 22 abr. 2004.
} 
referido cancelamento ocorreu em 2003. Desse modo, verifica-se que a despesa realizada em 2002 foi de 416 bilhões de reais e não o que constou no Balanço Orçamentário (422 bilhões de reais).

No Balanço Financeiro, as despesas de restos a pagar do exercício serão computadas na receita extra-orçamentária ${ }^{12}$ para compensar sua inclusão na despesa orçamentária $^{13}$ (Parágrafo único do art. 103 da Lei $n^{\circ}$. 4.320/64). Para Kohama (1999), essa operação contábil, ao menos da inscrição de despesas não processadas tem características de "despesa figurativa"14.

Do acima exposto, surge o questionamento que o objetivo geral investigará.

Que reflexos contábeis poderão decorrer do cancelamento das despesas públicas dos restos a pagar nas despesas que foram consideradas liquidadas $e$ divulgadas pelos poderes e órgãos da União?

\subsection{Objetivos e Relevância da Pesquisa}

O objetivo geral desta investigação foi analisar e evidenciar os reflexos contábeis decorrentes do cancelamento das despesas públicas dos restos a pagar nas despesas que foram consideradas liquidadas e divulgadas pelos poderes $e$ órgãos da União. Vinculados ao objetivo geral e ao problema desta investigação, os objetivos específicos são: revisar a literatura para conhecer o estado da arte na área do estudo; identificar o sistema informatizado contábil e o processo de contabilização das despesas de restos a pagar do Governo Federal; reconhecer o processo de orçamento das despesas públicas; demonstrar, por exercícios financeiros, os valores inscritos de despesas de restos a pagar pelos poderes e órgãos da União; analisar os reflexos contábeis decorrentes do cancelamento da conta Fornecedores de Exercícios Anteriores (passivo) e de Obrigações Não Processadas a Liquidar.

A relevância da pesquisa reside na possibilidade de abrir discussão técnico-profissional com os envolvidos com Contabilidade Pública, Orçamento, Controle Externo e Interno, Finanças das Entidades da Administração Pública, para aperfeiçoar os mecanismos de evidenciação da gestão pública a que a sociedade, proprietária, cliente $e$ usuária das informações, faz jus.

\subsection{Metodologia da Pesquisa}

A metodologia utilizada nesta pesquisa foi, quanto aos objetivos, a pesquisa exploratória; quanto aos procedimentos, a pesquisa bibliográfica e quanto à abordagem do problema, as pesquisas qualitativa e quantitativa.

Optou-se por utilizar o Coeficiente de Correlação de Pearson com o objetivo de analisar a correlação dos dados da pesquisa. Segundo Stevenson (1981), os dados contínuos (variáveis) podem assumir quaisquer valores num intervalo contínuo e Spiegel (1977) exemplifica como variáveis contínuas os pesos de 100 estudantes universitários.

Foram utilizadas as estatísticas F (ANOVA) e t (Student) para serem analisados os intervalos de confiança (testes de significância). A finalidade dos testes de significância é avaliar afirmações sobre os valores de parâmetros populacionais (STEVENSON, 1981).

Os cálculos dos testes estatísticos foram feitos com a utilização do software SPSS - Statistical Package for the Social Sciences - versão 12.0 e os diagramas (gráficos) de dispersão com o software Excel 2000.

\subsection{Fonte de Dados}

Os dados foram coletados dos Balanços Gerais da União (Orçamentos Fiscal e da Seguridade Social), no período de 1999 a 2003, disponibilizados pela Secretaria do Tesouro Nacional do Ministério da Fazenda ${ }^{15}$ nas Demonstrações das Despesas por Poder e Órgão e dos Restos a Pagar por Poder e Órgão.

\subsection{Hipóteses}

As hipóteses desta pesquisa foram as seguintes:

1ํ Hipótese:

O reflexo contábil decorrente do cancelamento das despesas de restos a pagar não é significativo em relação às despesas que foram consideradas liquidadas e divulgadas pelos poderes e órgãos da União. Hipótese nula $\mathrm{H}_{0}: \beta_{\mathrm{i}}=$ 0 (não existe relação: o parâmetro não é estatisticamente significativo). Hipótese alternativa $\mathrm{H}_{1}: \beta_{\mathrm{i}} \neq 0$ (existe relação: o parâmetro é estatisticamente significativo).

\section{2a Hipótese:}

A despesa de restos a pagar inscritas (totais) não é significativa em relação às que foram consideradas liquidadas e divulgadas pelos poderes e órgãos da União, sob o ponto de vista contábil. Hipótese nula $\mathrm{H}_{0}: \beta_{\mathrm{i}}=0$ (não existe relação: o parâmetro não é estatisticamente significativo). Hipótese alternativa $\mathrm{H}_{1}: \beta_{\mathrm{i}} \neq 0$ (existe relação: o parâmetro é estatisticamente significativo).

\section{3a Hipótese:}

O reflexo contábil decorrente do cancelamento das despesas de restos a pagar não é significativo em relação aos restos a pagar inscritos (totais) dos poderes e órgãos da União. Hipótese nula $\mathrm{H}_{0}: \beta_{\mathrm{i}}=0$ (não existe relação: o parâmetro não é estatisticamente significativo). Hipótese alternativa $\mathrm{H}_{1}: \beta_{\mathrm{i}} \neq 0$ (existe relação: o parâmetro é estatisticamente significativo). 


\section{FUNDAMENÇÃO TEÓRICA}

O orçamento é o principal instrumento do Poder Legislativo para controlar os gastos públicos. O princípio básico do orçamento é prever receitas e autorizar despesas (MACHADO, 2003). A sua aprovação está apoiada no regime de caixa ${ }^{16}$ (SILVA, 2003).

A Lei $n^{\circ}$. 4.320/64 não define, não conceitua as despesas, apenas classifica-as em categorias econômicas (despesas correntes ${ }^{17}$ e de capital18).

A despesa pública é definida como o conjunto de dispêndios do Estado ou de outra pessoa de Direito Público para o funcionamento dos serviços públicos e encargos assumidos no interesse geral da comunidade. Nesse sentido, a despesa, como parte do orçamento, compreende as autorizações para gastos com as várias atribuições e funções governamentais. Em outras palavras, as despesas públicas correspondem à distribuição e ao emprego das receitas para o custeio de diferentes setores da Administração e para os investimentos (LIMA; CASTRO, 2000; SILVA, 2000).

O conceito de despesa pública não atende ao conceito de despesa, sentido restrito, segundo a teoria contábil, visto não representar a utilização ou o consumo de bens e serviços no processo de produzir receitas (IUDÍCIBUS, 2004).

Segundo Slomski (2001), a orçamentação da despesa pública passará pelo processo de elaboração da Lei de Orçamento Anual (LOA), de estudo e aprovação, obedecido o Plano Plurianual (PPA) e a Lei de Diretrizes Orçamentárias (LDO).

As despesas devem ser empenhadas e pagas num mesmo exercício financeiro pelo princípio da anualidade, entretanto, verifica-se exceção à regra quando se admitem as despesas de restos a pagar $e$ as despesas de exercícios anteriores. A despesa processada de restos a pagar representa os compromissos que, ao terminar o exercício financeiro, já estavam em processo de pagamento. A despesa não processada ou simplesmente empenhada representa os compromissos que não cumpriram o estágio da liquidação da despesa a que se refere 0 art. 63 da própria Lei $n^{\circ}$. 4.320/64 ${ }^{19}$ (CRUZ et al., 2001).

Segundo Dias Filho (2000), as demonstrações contábeis empregam uma terminologia complexa e pouco acessível à maioria dos usuários.

ludícibus (2004), ao analisar a teoria do fundo, recomenda que seria altamente louvável que nossas instituições não lucrativas $e$ as entidades governamentais estudassem tal modelo, visto que nosso modelo de Con- tabilidade Pública é altamente complexo e, conseqüentemente, moroso.

Quanto às despesas de restos a pagar, a macrofunção 02.03.17 do Manual do Sistema de Administração Financeira do Governo Federal $\left(\right.$ SIAFI $\left.^{20}\right)$, estabelece os seguintes procedimentos:

- As despesas caracterizadas como Restos a Pagar se distinguem em processadas (liquidadas) e não processadas (não liquidadas);

- As liquidadas referem-se a créditos empenhados em que o credor já cumpriu todas as formalidades legais de habilitação do pagamento, estando representado contabilmente pelas compras do grupo OBRIGAÇÕES EM CIRCULAÇÃO;

- A conta 2.1.2.1.6.02.02 - NÃO PROCESSADAS A LIQUIDAR conterá os saldos remanescentes de Restos a Pagar do exercício anterior, os quais devem ser pagos ou cancelados pela Unidade Gestora (UG) até o dia 31 de dezembro do exercício subseqüente. O cancelamento será feito por meio da transação ${ }^{21}$ NE (NOTA DE EMPENHO), que indica, no campo ESPÉCIE", a opção "4". Caso isso não ocorra, serão baixados, automaticamente, pelo sistema por meio do evento 50.1.014;

- A inscrição de Restos a Pagar Não Processados será realizada, automaticamente, por meio dos eventos 50.1.468, 54.3.122 e 54.3.009, registrando os valores das despesas orçamentárias na transação CONBAIXSAL;

- A inscrição das despesas em Restos a Pagar é efetuada no orçamento de cada exercício de emissão da respectiva Nota de Empenho e cancelada no final do exercício subseqüente, permanecendo em vigor, no entanto, o direito do credor por 05 (cinco) anos, a partir da inscrição, quando, então, prescreverá.

Os eventos 50.1.468, 54.3.122 e 54.3.009 (usados na contabilização de restos a pagar não processados) têm como destaque, no roteiro de contabilização, a conta a débito - 3.X.X.X.X.XX.98 - RESTOS A PAGAR (X representa os tipos de despesas por categoria econômica) e a conta a crédito - 2.1.2.1.6.02.02 - RESTOS A PAGAR NÃO PROCESSADOS A LIQUIDAR.

Os restos a pagar processados são contabilizados, como destaque no roteiro de contabilização, a conta de

\footnotetext{
16 Regime de Caixa: considera como receitas ou despesas as efetivamente recebidas ou pagas, independentemente do fato gerador. Mensura o resultado financeiro de determinado período pela diferença entre os recebimentos e os pagamentos, permitindo o levantamento do fluxo de caixa.

17 Despesas correntes: classificam-se, nessa categoria, todas as despesas que não contribuam diretamente para a formação ou aquisição de um bem de capital. Ex: despesas com pessoal e encargos sociais, juros e encargos da dívida.

18 Despesas de capital: classificam-se, nessa categoria, aquelas despesas que contribuem diretamente para a formação ou aquisição de um bem de capital. Ex: investimentos inversões financeiras.

19 Art. 63. A liquidação da despesa consiste na verificação do direito adquirido pelo credor, tendo por base os títulos e documentos comprobatórios do respectivo crédito. 20 O SIAFI solucionou os problemas de confiabilidade das informações, que eram agravadas pelo fato de a contabilidade da União agregar o trabalho de mais de uma dezena de milhar de operadores. LIMA, Diana Vaz; CASTRO, Róbison Gonçalves. Contabilidade Pública - integrando União, Estados e Municípios (SIAFI e SIAFEM). São Paulo: Atlas, 2000 .

21 Transação representa os comandos de operacionalização do SIAFI.
} 
débito de despesa - 3.X.X.X.X.XX.XX (evento 51.1.XXX, sendo $X X X$ a variação do tipo de despesas) e a conta de crédito de obrigação - 2.1.2.1.1.02.00 - FORNECEDORES DO EXERCÍCIO ANTERIOR (evento 52.1.214).

O cancelamento dos restos não processados é procedido com os eventos 40.1.094 e 40.1.095, que apresentam como contas principais: a débito, a conta 2.1.2.1.6.02.02 RESTOS A PAGAR NÃO PROCESSADOS A LIQUIDAR e, a crédito, a conta 6.2.3.3.1.05.00 - RESTOS A PAGAR (conta contábil de resultado do sistema financeiro).

O cancelamento de restos a pagar processados é registrado com o evento $\mathbf{5 4 . 0 . 3 7 9}$, tendo como contas princi- pais: a débito, a conta 2.1.2.1.1.02.00 - FORNECEDO-

RES DO EXERCÍCIO ANTERIOR e, a crédito, a conta 6.2.3.3.1.04.00 - OBRIGAÇÕES DE EXERCÍCIOS ANTE-

RIORES (conta contábil de resultado do sistema financeiro).

O pagamento das despesas de restos a pagar processados e não processados não traz nenhum reflexo contábil para as informações dos valores de despesas realizadas (liquidadas) no Balanço Orçamentário de sua inscrição, pois foi concretizado o último estágio da despesa pública, ou seja, o pagamento. Desse modo, o valor informado como despesa liquidada foi pago (realizado).

\section{RESULTADOS DA PESQUISA E ANÁLISES}

A Tabela 10 representa as despesas liquidadas e os restos a pagar dos Poderes e Órgãos da União, excluídos os valores do refinanciamento da dívida pública da União.

Observe-se uma evolução das despesas liquidadas de $55 \%$ de 1999 a 2003 e uma diminuição de $23 \%$ dos restos a pagar inscritos (processados e não processados). Houve, também, aumento de cancelamento das despesas de restos a pagar.

As despesas reais (despesas liquidadas menos os valores cancelados nos anos seguintes) dos poderes e órgãos da União, não computados os valores que ficaram a pagar, são esclarecidos na Tabela $2 \mathbf{0}$.

Considera-se despesa liquidada real, nesta investigação, o valor das despesas que realmente foram liquidadas, ou seja, o material e/ou serviço foi entregue/prestado e o credor tem direito ao pagamento.
Observe-se uma redução das despesas nos anos de 2000 de 0,22\%; 2001 de 0,7\%; 2002 de 1,5\% e em 2003 de 1,6\% (Tabela 2) na comparação entre as despesas liquidadas e as despesas reais.

O Gráfico $1 \bullet$ demonstra a comparação das despesas liquidadas com as despesas reais (excluídos os restos a pagar cancelados), no período de 1999 a 2003, dos Poderes da União.

A Tabela $3 \bullet$ representa os resultados estatísticos da aplicação da hipótese: o reflexo contábil decorrente do cancelamento das despesas de restos a pagar não é significativo em relação às que foram consideradas liquidadas e divulgadas pelos poderes e órgãos da União. Hipótese nula $\mathrm{H}_{0}: \beta_{\mathrm{i}}$ $=0$ (não existe relação: o parâmetro não é estatisticamente significativo). Hipótese alternativa $\mathrm{H}_{1}: \beta_{\mathrm{i}} \neq 0$ (existe relação: o parâmetro é estatisticamente significativo).

Tabela 1 ॥xecução das despesas liquidadas dos Poderes e Órgãos da União X restos a pagar dos Poderes e Órgãos da União (1999 - 2003) - R\$ milhares

\begin{tabular}{c|c|c|c}
\multirow{2}{*}{ ANO } & \multirow{2}{*}{ DESPESAS LIQUIDADAS } & \multicolumn{2}{|c}{$\begin{array}{c}\text { DESPESAS DE RESTOS A PAGAR } \\
\text { (PROCESSADOS E NÃO PROCESSADOS) }\end{array}$} \\
\cline { 3 - 4 } & & $\begin{array}{c}\text { INSCRITOS } \\
\text { CANCELADOS }\end{array}$ & 0 \\
\hline 2999 & 319.293 .246 & 23.414 .532 & 682.484 \\
\hline 2000 & 315.420 .569 & 24.785 .461 & 2.679 .061 \\
\hline 2001 & 383.389 .210 & 15.009 .651 & 6.677 .491 \\
\hline 2003 & 439.097 .026 & 25.298 .180 & 7.625 .377
\end{tabular}

Fonte: STN - adaptado

Tabela 2 Despesas reais dos Poderes e Órgãos da União - R\$ milhares

\begin{tabular}{c|c} 
ANO & DESPESAS REAIS \\
1999 & 319.293 .246 \\
\hline 2000 & 314.738 .085 \\
\hline 2001 & 380.710 .149 \\
\hline 2002 & 432.419 .535 \\
\hline 2003 & 485.362 .925
\end{tabular}

Fonte: Elaboração própria 


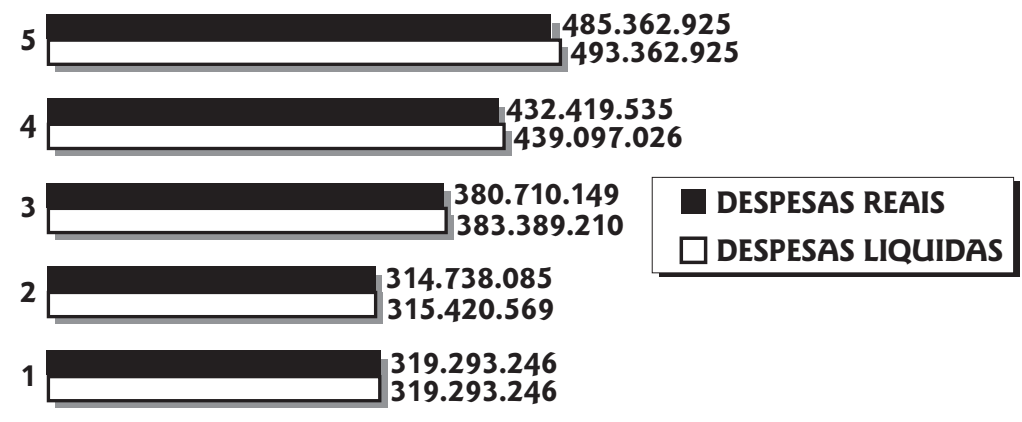

Fonte: Elaboração própria

Gráfico 1 - Comparação de despesas liquidadas e despesas reais dos Poderes e Órgãos da União

Tabela 3 Resumos estatísticos das despesas liquidadas dos Poderes e Órgãos da União X restos a pagar cancelados dos Poderes e Órgãos da União (1999 - 2003)

\begin{tabular}{l|l} 
Variável Dependente: RP CANCELADOS & Variável Independente: DESPESAS LIQUIDADAS \\
\hline Correlação de Pearson & $\mathrm{r}=0,980$ \\
\hline R quadrado & $\mathrm{R}^{2}=0,961(96,1 \%$ explica e 3,9\% outros fatores $)$ \\
\hline Teste $\mathrm{F}$ & $\mathrm{F}_{\text {calculado }}=74,515 \mathrm{~F}_{\text {tabela }}=5,32$ graus de liberdade: $1,8-$ nível 0,05 \\
\hline Teste $\mathrm{t}$ & $\mathrm{t}_{\text {calculado }}=8,632 \mathrm{t}_{\text {tabela }}=3,182( \pm 3,182)$ grau de liberdade: $3-$ nível 0,05
\end{tabular}

Fonte: Elaboração própria

Conclui-se pela rejeição da hipótese nula e aceitação da hipótese alternativa. Existe um relacionamento significativo estatisticamente entre os restos a pagar cancelados e as despesas liquidadas dos Poderes e Órgãos da União. O coeficiente de determinação explica o relacionamento em $96,1 \%$.

O estudo do reflexo contábil do cancelamento das despesas de restos a pagar em relação às despesas liquidadas é significativo. O coeficiente de correlação de Pearson de 0,980 , muito próximo de 1 , convalida o relacionamento, que também é referendado pelos testes de hipóteses: o $\mathrm{F}_{\text {cal- }}$. culado $(74,515)$ supera em muito o $F_{\text {tabelado }}(5,32)$ e também 0 $\mathrm{t}_{\text {calculado }}(8,632)$ é maior que $0 \mathrm{t}_{\text {tabelado }}$, conforme demonstram as Figuras 10 e 20.

O Gráfico $2 \bullet$ demonstra o relacionamento positivo entre as variáveis dos restos a pagar cancelados (variável dependente y) e as despesas liquidadas (variável indepen-

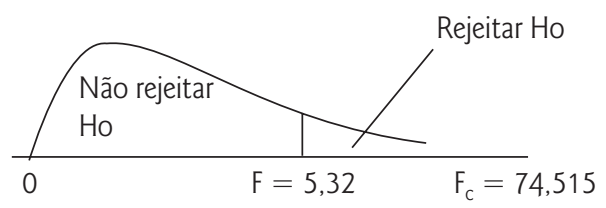

Fonte: Elaboração própria

Figura 1 Teste F (ANOVA) - Despesas liquidadas $X$ restos a pagar cancelados dos Poderes e Órgãos da União dente $\mathrm{x}$ ). Observe-se que os pontos de relacionamentos das variáveis estão próximos da linha de tendência: linha preta (gráfico de dispersão).

A Tabela $4 \bullet$ representa os resultados estatísticos da aplicação da hipótese: a despesa de restos a pagar inscritas (totais) não é significativa em relação às despesas que foram consideradas liquidadas e divulgadas pelos poderes e órgãos da União, sob o ponto de vista contábil. Hipótese nula $\mathrm{H}_{0}: \beta_{\mathrm{i}}$ $=0$ (não existe relação: o parâmetro não é estatisticamente significativo). Hipótese alternativa $\mathrm{H}_{1}: \beta_{\mathrm{i}} \neq 0$ (existe relação: o parâmetro é estatisticamente significativo).

Conclui-se pela aceitação da hipótese nula. O relacionamento negativo entre as despesas dos restos a pagar inscritos (totais) e as despesas liquidadas não é estatisticamente significativo. Os testes de hipóteses apresentaram os valores calculados inferiores aos tabelados (Figuras $3 \bullet$ e $4 \bullet$ ).

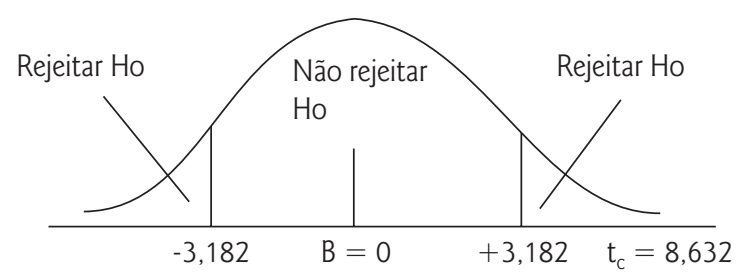

Fonte: Elaboração própria

Figura 2 Teste $t$ (Student) - Despesas liquidadas $X$ restos a pagar cancelados dos Poderes e Órgãos da União 


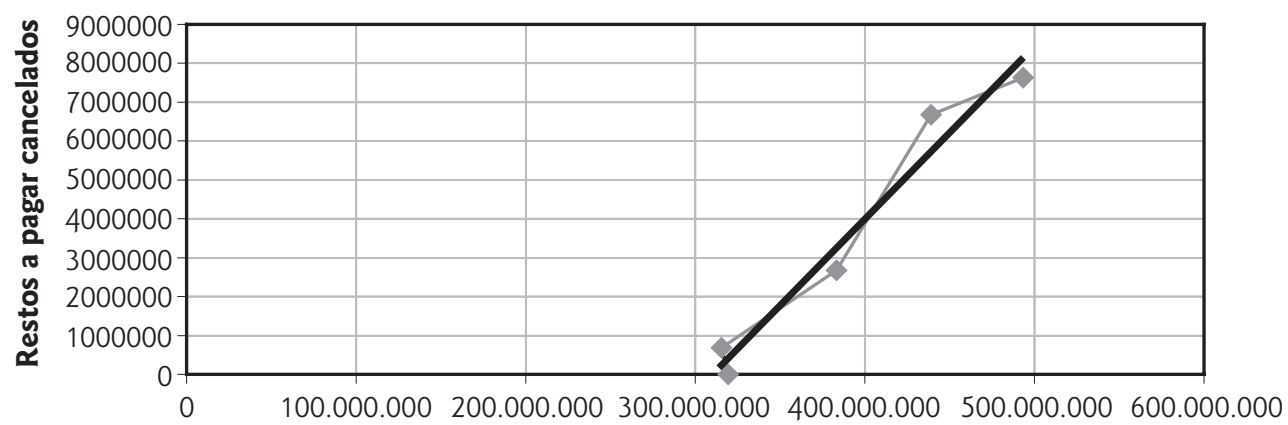

Despesas liquidadas

Fonte: Elaboração própria

Gráfico 2 ॥ Despesas liquidadas X restos a pagar cancelados dos Poderes e Órgãos da União

Tabela 4 Resumos estatísticos das despesas liquidadas dos Poderes e Órgãos da União X restos a pagar inscritos (total) dos Poderes e Órgãos da União (1999 - 2003)

\begin{tabular}{l|l} 
Variável Dependente: RP INSCRITOS (TOTAL) & Variável Independente: DESPESAS LIQUIDADAS \\
Correlação de Pearson & $\mathrm{r}=-0,360$ \\
\hline $\mathrm{R}$ quadrado & $\mathrm{R}^{2}=0,13(13 \%$ explica e $87 \%$ outros fatores $)$ \\
\hline Teste $\mathrm{F}$ & $\mathrm{F}_{\text {calculado }}=0,447 \mathrm{~F}_{\text {tabela }}=5,32$ graus de liberdade: $1,8-$ nível 0,05 \\
\hline Teste $\mathrm{t}$ & $\mathrm{t}_{\text {calculado }}=0,668 \mathrm{t}_{\text {tabela }}=3,182( \pm 3,182)$ grau de liberdade: $3-$ nível 0,05
\end{tabular}

Fonte: Elaboração própria

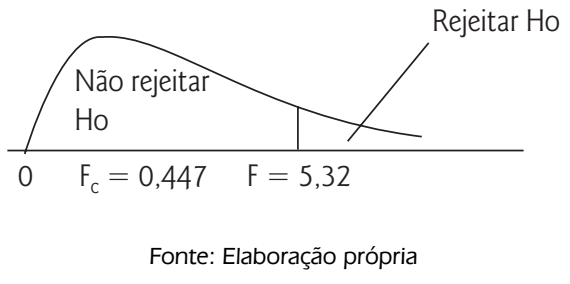

Figura 3 Teste F (ANOVA) - Despesas liquidadas $X$ restos a pagar inscritos (totais) dos Poderes e Órgãos da União
O Gráfico $3 \bullet$ demonstra a ausência de relacionamento. O relacionamento entre as variáveis $x$ e y estão em pontos distantes da linha de tendência (linha preta) pela qual a distribuição normal bivariada deve se apresentar.

A Tabela $5 \bullet$ representa os resultados estatísticos da aplicação da hipótese: o reflexo contábil decorrente do cancelamento das despesas de restos a pagar não é significativo em relação aos restos a pagar inscritos (totais) dos poderes e órgãos da União. Hipótese nula $\mathrm{H}_{0}: \beta_{\mathrm{i}}=0$ (não existe relação: o parâmetro não é estatisticamente significativo). Hipótese alternativa $\mathrm{H}_{1}: \beta_{\mathrm{i}} \neq 0$ (existe relação: 0 parâmetro é estatisticamente significativo).

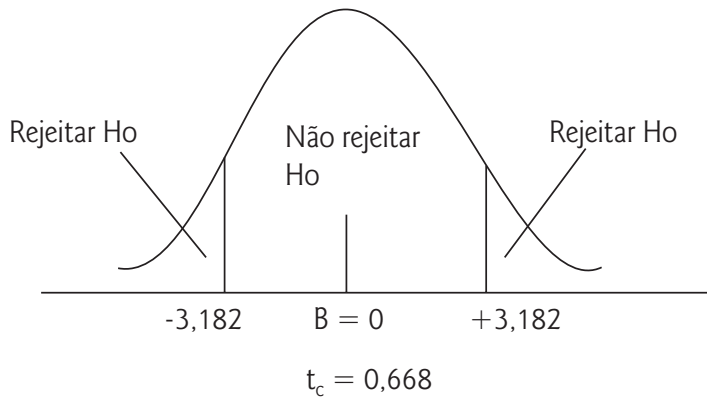

Fonte: Elaboração própria

Figura 4 Teste t (Student) - Despesas liquidadas $X$ restos a pagar inscritos (totais) dos Poderes e Órgãos da União
Conclui-se pela aceitação da hipótese nula. O parâmetro de relacionamento não é estatisticamente significativo. A hipótese de não relacionamento é aceita. Os testes de hipóteses convalidaram tal assertiva (Figuras 50 e $6 \bullet$ ), bem como o Gráfico $4 \bullet$.

Observe-se que os valores das variáveis analisadas estão em pontos distantes da linha de tendência. Os pontos de relacionamentos estão fora da distribuição normal bivariada: linha preta (Gráfico 4). 


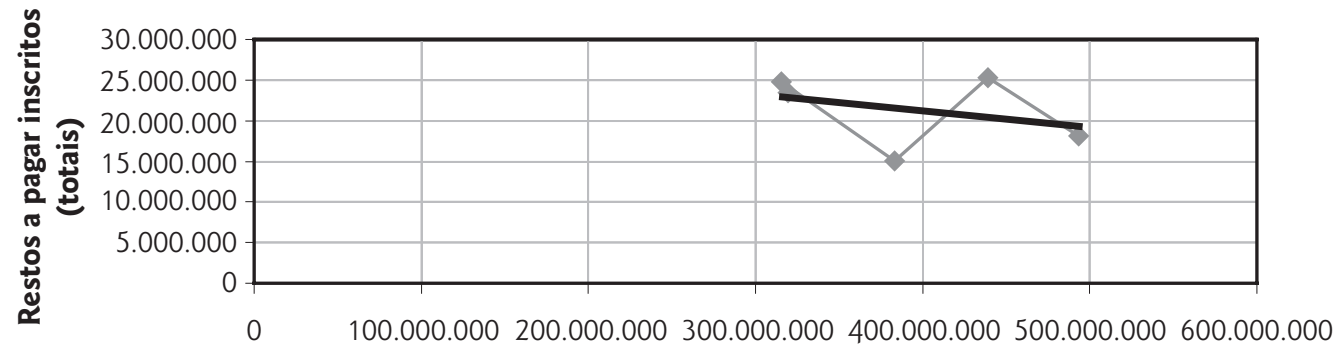

\section{Despesas liquidadas}

Fonte: Elaboração própria

Gráfico 3 || Despesas liquidadas $X$ restos a pagar totais dos Poderes e Órgãos da União

Tabela 5 Resumos estatísticos dos restos a pagar cancelados dos Poderes e Órgãos da União X restos a pagar inscritos (total) dos Poderes e Órgãos da União (1999 - 2003)

\begin{tabular}{l|l} 
Variável Dependente: RP CANCELADOS & Variável Independente: RP INSCRITOS (TOTAL) \\
Correlação de Pearson & $\mathrm{r}=-0,200$ \\
\hline R quadrado & $\mathrm{R}^{2}=0,04(4 \%$ explica e $96 \%$ outros fatores $)$ \\
\hline Teste $\mathrm{F}$ & $\mathrm{F}_{\text {calculado }}=0,125 \mathrm{~F}_{\text {tabela }}=5,32$ graus de liberdade: $1,8-$ nível 0,05 \\
\hline Teste $\mathrm{t}$ & $\mathrm{t}_{\text {calculado }}=0,354 \mathrm{t}_{\text {tabela }}=3,182( \pm 3,182)$ grau de liberdade: $3-$ nível 0,05
\end{tabular}

Fonte: Elaboração própria

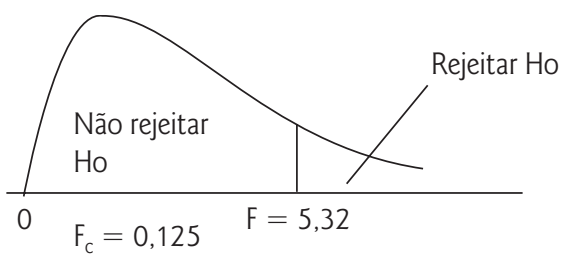

Fonte: Elaboração própria

Figura 5 - Teste $\mathrm{F}$ (ANOVA) - Restos a pagar cancelados $X$ restos a pagar inscritos (totais) dos Poderes e Órgãos da União

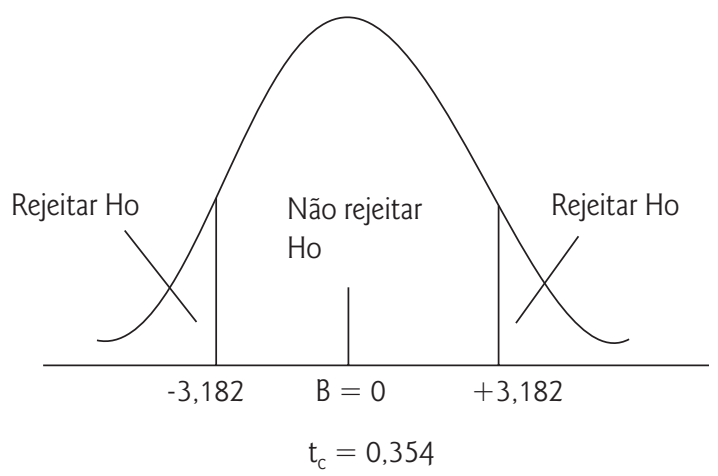

Fonte: Elaboração própria

Figura 6 - Teste $t$ (Student) - Restos a pagar cancelados $X$ restos a pagar inscritos (totais) dos Poderes e Órgãos da União

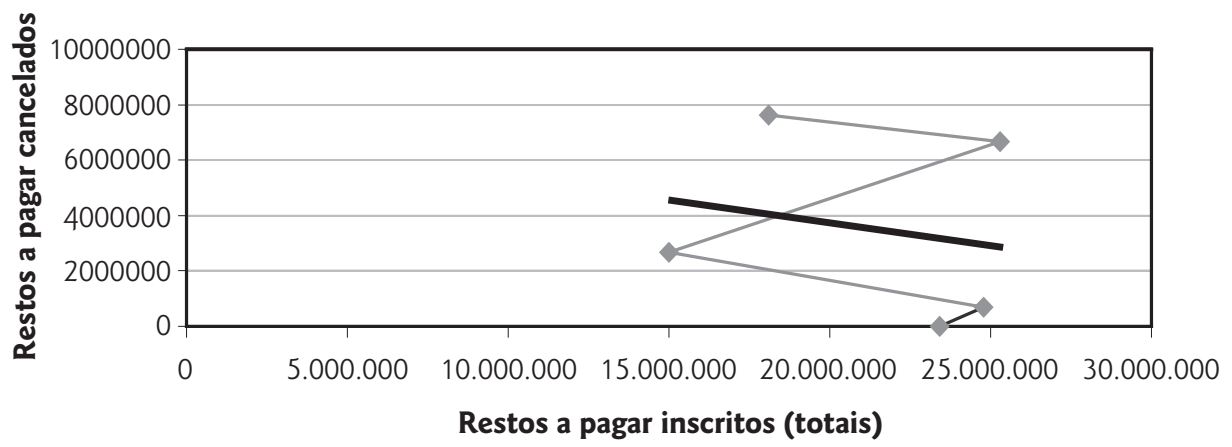

Fonte: Elaboração própria

Gráfico 4 || Restos a pagar cancelados X restos a pagar totais dos Poderes e Órgãos da União 


\section{REFLEXOS CONTÁBEIS DECORRENTES DO CANCELAMENTO DAS DESPESAS DOS RESTOS A PAGAR - CONTAS CONTÁBEIS}

A Tabela 60 evidencia as despesas liquidadas dos Poderes da União e os respectivos cancelamentos da conta Fornecedores de Exercícios Anteriores (passivo), no período de 1999 a 2003.

Observe-se, na Tabela 6, que, nos anos de 2002 e 2003, os Poderes e Órgãos da União cancelaram valores da conta Fornecedores de Exercícios Anteriores (passivo) nos percentuais de $0,22 \%$ e $0,13 \%$, respectivamente.

O cancelamento das referidas exigibilidades representa o não pagamento de despesas liquidadas de materiais e serviços em que o credor havia entregado o material e/ou prestado o serviço (processos de despesas realizadas: Nota de Empenho e Nota Fiscal de Material/Serviço).

Os reflexos contábeis decorrentes do cancelamento foram:

\section{1) Ano de liquidação da despesa:}

- diminuição das despesas que foram consideradas liquidadas e divulgadas pelos Poderes e Órgãos da União no Balanço Orçamentário de 2002 e 2003. Desse modo, as despesas reais (despesas liquidadas diminuídas das despesas canceladas) foram, respectivamente, de $\mathrm{R} \$ 438.138 .394$ (milhares) e $R \$ 492.706 .857$ (milhares).

- incorporação de ativos a maior (despesas de materiais) no sistema patrimonial (Demonstração das Variações Patrimoniais de 2002 e 2003).

2) Ano de cancelamento da obrigação - Fornecedores de Exercícios Anteriores (passivo - conta 2.1.2.1.1.02.00):
- aumento do sistema financeiro (conta 6.2.3.3.1.04.00 - Obrigações de Exercícios Anteriores - Demonstração das Variações Patrimoniais);

- estorno (baixa) da conta 2.1.2.1.1.02.00 - Fornecedores de Exercícios Anteriores (passivo).

A Tabela 70 evidencia as despesas liquidadas dos Poderes e Órgãos da União e os respectivos cancelamentos de restos a pagar não processados (conta 21.2.1.6.02.02 - Obrigações Não Processadas a Liquidar).

Observe-se, na Tabela 7, que, no período de 2000 a 2003, foram canceladas despesas de restos a pagar não processadas em percentuais de 0,22\%; 0,70\%; $1,30 \% \mathrm{e}$ $1,41 \%$; respectivamente.

O cancelamento da conta 2.1.2.1.6.02.02 - Obrigações Não Processadas a Liquidar representa a baixa de uma obrigação a ser processada, em que havia sido emitida apenas a Nota de Empenho (o material e/ou o serviço não havia sido entregue/prestado).

Os reflexos contábeis decorrentes do cancelamento foram:

1) Ano de inscrição da despesa de restos a pagar não processadas (eventos 50.1.468, 54.3.122 e 54.3.009):

- diminuição das despesas que foram consideradas liquidadas e divulgadas pelos Poderes da União no Balanço Orçamentário de 2000 a 2003. Desse modo, as despesas reais (despesas liquidadas diminuídas das despesas de restos a pagar não processadas) foram

Tabela 6 Execução das despesas liquidadas dos Poderes e Órgãos da União e o cancelamento da conta Fornecedores de Exercícios Anteriores (passivo) - R\$ milhares

\begin{tabular}{c|c|c}
\hline ANO & DESPESAS LIQUIDADAS & $\begin{array}{c}\text { RESTOS A PAGAR PROCESSADOS CANCELADOS } \\
\mathbf{( 2 . 1 . 2 . 1 . 1 . 0 2 . 0 0 )}\end{array}$ \\
\hline 1999 & 319.293 .246 & 0 \\
\hline 2000 & 315.420 .569 & 0 \\
\hline 2001 & 383.389 .210 & 0 \\
\hline 2002 & 439.097 .026 & 958.632 \\
\hline 2003 & 493.362 .925 & 656.068
\end{tabular}

Fonte: STN - adaptado

Tabela 7 Execução das despesas liquidadas dos Poderes e Órgãos da União e o cancelamento da conta Obrigações Não Processadas a Liquidar - RS milhares

\begin{tabular}{c|c|c} 
ANO & DESPESAS LIQUIDADAS & $\begin{array}{c}\text { RESTOS A PAGAR NÃO PROCESSADOS } \\
\text { CANCELADOS (2.1.2.1.6.02.02) }\end{array}$ \\
\hline 1999 & 319.293 .246 & 0 \\
\hline 2000 & 315.420 .569 & 682.484 \\
\hline 2001 & 383.389 .210 & 2.679 .061 \\
\hline 2002 & 439.097 .026 & 5.718 .859 \\
\hline 2003 & 493.362 .925 & 6.969 .309
\end{tabular}

Fonte: STN - adaptado 
de $R \$ 314.738 .085$ (milhares), $R \$ 380.710 .149$ (miIhares), $R \$ 433.378 .167$ (milhares), $R \$ 486.393 .616$ (milhares), respectivamente. As despesas reais totais (despesas liquidadas excluídos os restos a pagar totais cancelados) constam da Tabela 2.

2) Ano de cancelamento da conta 2.1.2.1.6.02.02 - Obrigações Não Processadas a Liquidar:
- aumento no sistema de resultado do sistema financeiro (despesas de serviços - conta 6.2.3.3.1.05.00 - Restos a Pagar);

- cancelamento da conta 2.1.2.1.6.02.02 - Obrigações Não Processadas a Liquidar.

\section{CONSIDERAÇÕES FINAIS, RECOMENDAC̣ÕES E CONCLUSÃO}

A pesquisa, em atenção ao objetivo formulado, evidenciou, por análises descritivas e estatísticas, que a hipótese alternativa sobre o reflexo contábil decorrente do cancelamento das despesas de restos a pagar é significativo em relação às despesas que foram consideradas liquidadas $e$ divulgadas pelos poderes e órgãos da União, sendo aceitas as demais hipóteses nulas (os parâmetros não são estatisticamente significativos).

Considerando-se que durante a investigação, foram observadaos vários fatos ligados ao foco delineado, mas que não foi possível serem feitas análises (delimitação da pesquisa), recomendam-se futuras pesquisas, abordando os seguintes aspectos:

- análises das conseqüências jurídicas, administrativas e econômicas decorrentes do cancelamento da conta de Fornecedores de Exercícios Anteriores (passivo) e da conta Obrigações Não Processadas a Liquidar, abordando o ponto de vista dos credores, a credibilidade da Nota de Empenho, o relacionamento devedor e credor e a teoria dos contratos;

- investigação do problema com a delimitação nas contas públicas estaduais e municipais (dados disponibilizados na Internet);

- repetição da presente pesquisa com séries históricas que abranjam períodos de vários anos, desde que a Secretaria do Tesouro Nacional, assim, o disponibilize;

- análises dos restos a pagar totais (convênios a pagar, contrato de programa de repasse a pagar, obrigações vinculadas a projetos especiais, pessoal a pagar). Nesta pesquisa, somente foram consideradas as despesas com fornecedores de bens e serviços, classificadas como investimentos, inversões financeiras e outras despesas correntes;

- questões relacionadas aos preços cobrados pelos credores para serviços e materiais realizados/fornecidos de junho a agosto com a inscrição de restos a pagar obrigatória (restos a pagar programados) para o gestor público efetuar o pagamento com previsão para janeiro e/ou fevereiro do ano seguinte;

- reflexo contábil da apropriação das contas de despesas dos restos a pagar não processados de materiais e serviços nas contas públicas do sistema de resultado;

- apuração de resultado no setor público: análise comparativa entre as Demonstrações das Variações Patrimoniais (setor público) e as Demonstrações do Resultado do Exercício (setor privado).

Conclui-se que as despesas públicas que foram consideradas liquidadas e divulgadas pelos poderes e órgãos, no período analisado, apresentaram, nas demonstrações analisadas, informações que não correspondem aos valores de despesas reais e considerando-se que a contabilidade pública brasileira rege-se pelas mesmas leis, o problema levantado poderá ocorrer na administração pública estadual e municipal.

\section{Referências Bibliográficas}

BRASIL. Lei no. 4.320, de 17 de março de 1964. Estatui normas gerais de direito financeiro para elaboração e controle dos orçamentos e balanços da União, dos Estados, dos Municípios e do Distrito Federal. Diário Oficial da República Federativa do Brasil, Brasília, 23 de março de 1964.

Ministério da Fazenda - Secretaria do Tesouro Nacional. Balanço Geral da União. Disponível em: <www.stn.fazenda.gov.br/ contabilidade_governamental/gestao_orcamentaria.asp >. Acesso em 20 abr. 2005.

Ministério da Fazenda - Secretaria do Tesouro Nacional - Manual do SIAFI - Macrofunções: 02.03.18 - Encerramento do exercício, 02.03 .17 - Restos a pagar; 02.03.19 - Demonstrações contábeis e 02.12.05 - Roteiro para regularização de pendências referentes às demonstrações contábeis.

CRUZ, Flávio da et al. (Org). Comentários à Lei no 4.320 e ao substitutivo do projeto de Lei no . 135/96. 2. ed. São Paulo: Atlas, 2001.

. Auditoria governamental. São Paulo: Atlas, 1997.

DIAS FILHO, José Maria. A linguagem utilizada na evidenciação contábil: uma análise de sua compreensibilidade à luz da teoria da comunicação. Caderno de Estudos da FIPECAFI, São Paulo, v. 13, n. 24, p. 38 - 49, jul./dez. 2000.

GIACOMONI, James. Orçamento público. 12. ed. São Paulo: Atlas, 2003. 
IUDÍCIBUS, Sérgio de. Teoria da Contabilidade. 7. ed. São Paulo: Atlas, 2004.

KOHAMA, Heilio. Contabilidade pública: teoria e prática. 6. ed. São Paulo: Atlas, 1998.

Balanços públicos: teoria e prática. São Paulo: Atlas, 1999.

LENZA, Pedro. Direito constitucional esquematizado. 7. ed. São Paulo: Método, 2004.

LIMA, Diana Vaz; CASTRO, Róbison Gonçalves. Contabilidade Pública - integrando União, Estados e Municípios (SIAFI e SIAFEM). São Paulo: Atlas, 2000.

MACHADO, Nelson. Restos a pagar: o impacto dos artigos 41 e 42 da lei de responsabilidade fiscal na gestão orçamentária e financeira. BNDES. Disponível em: <http://www.federativo.bndes.gov.br/f_estudo.htm>. Acesso em: 11 dez. 2003.

MEIRELLES, Hely Lopes. Direito administrativo brasileiro. 16. ed. São Paulo: Revista dos Tribunais, 1991.

REIS, Heraldo da Costa. Em busca da transparência na contabilidade governamental. Revista de Administração Municipal, Rio de Janeiro, v. 39, n. 202, p. 6 - 16, jan./mar. 1992.

RIBEIRO FILHO, José Francisco. Uma análise contábil da lei de responsabilidade fiscal sob a ótica da teoria de gestão econômica. Revista Brasileira de Contabilidade, Brasília, ano XXX, n. 132, p. 57 - 71, nov./dez. 2001.

RIBEIRO, Marco Túlio José de Barros; RIBEIRO FILHO, José Francisco; FRAGOSO, Adriana Rodrigues. Comunicação em contabilidade: uma abordagem estatística utilizando representações gráficas. In: CONGRESSO USP DE CONTROLADORIA E CONTABILIDADE, 3., 2003, São Paulo. Anais... São Paulo: EAC/FEA/USP, 2003. CD-ROM.

SILVA, Lino Martins da. Reflexões sobre as práticas contábeis em tempo de lei de responsabilidade fiscal. BNDES. Disponível em: <http://www. federativo.bndes.gov.br/f_estudo.htm>. Acesso em 11 dez. 2003.

Contabilidade governamental - um enfoque administrativo. 4 ed. São Paulo: Atlas, 2000.

SLOMSKI, Valmor. Manual de Contabilidade Pública - em enfoque na Contabilidade Municipal. São Paulo: Atlas, 2001.

SPIEGEL, Murray Ralph. Estatística: resumo da teoria. São Paulo: McGraw-Hill do Brasil, 1977.

STEVENSON, William J. Estatística aplicada à administração. São Paulo: Harbra, 1981.

\section{NOTA - Endereço dos autores}

